\title{
Transthyretin familial amyloid polyneuropathy: delineating the individual disease risk to improve management of patients and carriers
}
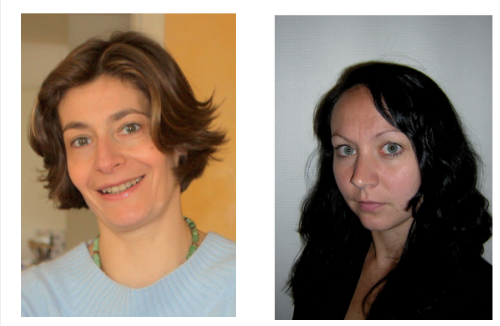

“...the factors, genetic or otherwise, which influence the phenotype

variation...remain

essentially unknown."

Violaine Planté-Bordeneuve ${ }^{\dagger 1} \&$ Nina Norgren $^{2}$

IService de Neurologie, Assistance Publique Hopitaux de Paris Centre Hospitalo Universitaire Henri Mondor

51 avenue de Lattre de Tassigny, 94000 Créteil, France

2Department of Public Health \& Clinical Medicine, Umea University, Umea, Sweden

tAuthor for correspondence: Tel.: +33 149814312 - Fax: +33 149812326 - violaine.plante@hmn.aphp.fr

\section{Transthyretin-familial amyloid polyneuropathy disease}

Transthyretin (TTR) familial amyloid polyneuropathy is the most severe inherited systemic amyloidosis of adulthood with autosomal dominant transmission. It is characterized by extracellular deposition of amyloid substance made up of fibrillar TTR [1]. Although systemic, the amyloid process targets mainly the peripheral nervous system and cardiac tissues. The clinical expression is therefore a progressive, disabling sensory-motor and autonomic axonal neuropathy with gait impairment after $3-5$ years, with a carpal tunnel syndrome that may occur concurrently [1,2]. A cardiac involvement is most frequently observed $(80 \%)$, whereas renal or ocular manifestations are seen in approximately $10 \%$ of cases $[2,3]$. Overall, the average survival is $10-12$ years $[1-4]$. The disease, initially described in Northern Portugal, then in Sweden and Japan, is now diagnosed throughout Europe and more widely across the world (i.e., in the USA, South America and Eastern Asia) [4].

TTR is mainly produced by the liver and assembled into soluble tetramers that normally handle the transport of thyroxin and retinol binding protein. Liver transplantation is currently the only therapeutic approach in this devastating disease [5], although, recently, less invasive pharmacological strategies have been developed. These molecules bind specifically to the tetramers, increasing their stability and preventing their dissociation into monomers, which is the major step in amyloid formation [6].
Thus, tafamidis, a drug chaperone of TTR, with an oral prescription was demonstrated to significantly slow down the neuropathic process in TTR-Val30Met patients, at an early stage of sensory motor neuropathy $[6,7]$. In addition, the product was well tolerated.

\section{"It seems likely that the effect is not due to one specific factor, but rather to a combination of both environmental and genetic factors."}

The TTR gene is of small size, including four exons. At present, the full sequencing of the gene has become an essential tool for the diagnosis of sensory motor neuropathy. It has also opened access to predictive genetic testing. Among 100 missense point mutations identified [101], the TTR-Val30Met is by far the most frequent worldwide and virtually the only one detected in Portugal and in Sweden. By contrast, an important heterogeneity of TTR variants is found in Japan, along with the TTRVal30Met [4]. Surprisingly, notable phenotypic differences, particularly at the age of first onset of symptoms, are observed even among carriers of the Val30Met variant. Thus, in Northern Portugal, where the largest focus of the disease has been studied, the mean age of onset is 33 years of age [8], whereas in Sweden, patients develop their symptoms on average at 56 years of age, with a male:female ratio of $2: 1$ [9]. In Japan, Val30Met families with young onset are

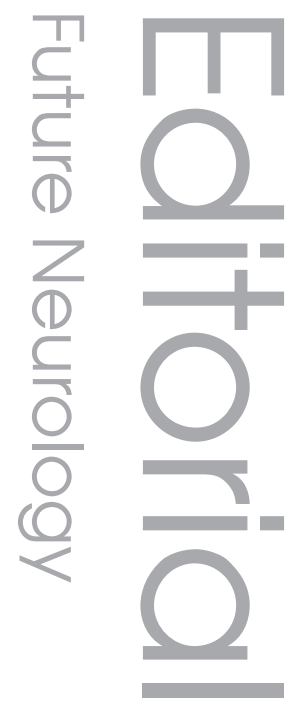

\section{Keywords}

- amyloidosis = carrier risk

- genetics " penetrance

- peripheral neuropathy

- transthyretin

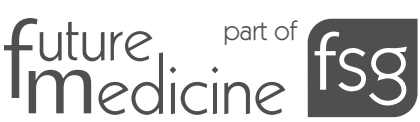


observed in two limited areas (Arao district and Ogawa village) with a phenotype similar to the one observed in Portugal and an anticipation phenomenon $[3,10,11]$. In addition, late onset (mean age: 62 years) Val30Met cases are distributed across the country and often present with no family history and a high male:female ratio of $10: 1[10,11]$.

\section{Delineating individual risk through penetrance studies}

The genotypic-phenotypic correlations are unclear. The factors, genetic or environmental, which influence the phenotype variation (i.e., the discrepancy of age of onset in TTRVal30Met families of different geographic origin) remain essentially unknown. In this setting, delineating the individual disease risk is important to improve the management of patients and carriers. In addition, it will contribute to the understanding of those factors underlying the disease expression.

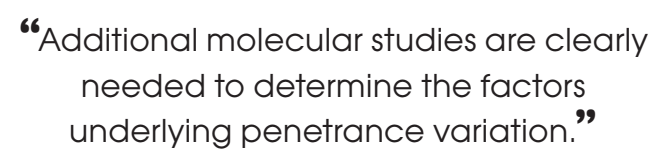

To address this question, it is important to estimate the penetrance of mutations (i.e., the risk of mutation carrier of being affected in populations from different geographical origins). Owing to this, an unbiased method of segregation analysis was used in TTR familial amyloid polyneuropathy (FAP) kindreds from Portugal, Brazil, Sweden and France [12]. In all these populations, an incomplete penetrance was found at 80 years of age, which reached approximately $85 \%$ in families from Portugal, Brazil and France, and only $69 \%$ in Swedish kindreds. At intermediate ages, striking differences were observed between populations. For instance, at 50 years of age, penetrance was $60 \%$ in Portuguese families, whereas it was only 18 and $11 \%$ in French and Swedish families, respectively [13-15]. These differences were not accounted for by a difference of genotype at the TTR gene [14]. Interestingly, a subsequent analysis in the Swedish families demonstrated a significantly higher penetrance when the mutation was inherited from the mother than from the father [15]. The same trend was also detected in the Portuguese and in the French samples [16]. Identifying the factors, genetic or not, which can underlie these differences has become a major challenge. Arguments for environmental factors are scarce. Differences in penetrance observed between two endemic areas in Sweden along with reports on discordant penetrance in pairs of monozygotic twins might support this hypothesis $[17,18]$. On the other hand, penetrance function was found to be superimposed in Portuguese and Brazilian population samples, although there were striking differences in environmental influences [15]. Careful studies to gather further insights are not available here.

\section{Delineating the individual risk at the molecular genetics level}

The individual genetic background might also be involved in the observed discrepancies in penetrance, and the role of modifier genes has been hypothesized but no such genes have as yet been identified. The finding of higher penetrance when the disease (TTR-FAP) is maternally inherited could be due to an imprinting phenomenon (i.e., a difference in expression of the mutated allele dependent on the gender of the parent who transmitted the mutation). This could be owing to some differential methylation patterns. However, we did not find any imprinted genes within the TTR region 18q11.2-12 in humans [16].

On the other hand, as mitochondrial DNA is maternally transmitted, mitochondria could also play a role in this differential expression. An association between mitochondrial haplogroup K and an early onset of the disease was detected in Swedish and French FAP-patients [19]. Furthermore, in a model proposed by Bonaïti et al., the effect of gender of the transmitting parent was further investigated, by modeling penetrance function under various hypotheses of transmission (i.e., a modifier mitochondrial DNA polymorphism and/or a parent of origin [imprinting effect] in samples of Portuguese and Swedish families) [20]. According to this model, a mitochondrial polymorphism could entirely explain the difference in penetrance for the Portuguese patients, and partly in the Swedish patients, with a clear residual parent-of-origin effect in the latter population [20].

Unraveling modifying genetic factors related to the mitochondria is a difficult task. As of yet, sequencing the entire mitochondrial DNA in individuals with TTR-Val30Met of both parental origins has not revealed any significant differences [Norgren $N$ \& Olsson M, unpublished data]. Alternatively, since mitochondria have been implicated in neurodegenerative diseases such as Alzheimer's and Parkinson's disease [21], we now consider searching for mitochondrial dysfunction by studying the activity of mitochondrial oxidative phosphorylation. 
Other approaches such as microarray technology might be relevant. Saraiva et al. performed a transcriptome analysis on salivary gland biopsies along with immunohistochemistry to link molecular patterns with the disease onset [22]. They demonstrated an activation of ERK1/2 pathway through receptor for advanced glycation endproducts in TTR-FAP patients, a pathway that could possibly lead to neurodegeneration. Similarly, an upregulation of Extracellular matrix proteins was found in patients compared with controls [23]. Finally, as the amyloid deposit consists of a protein network including HSPG2, SAP and ApoE, a candidate gene approach was performed in a large association study, using polymorphisms located in these genes and/or sequencing other players such as RBP4, APCS, SAA1 and SAA2 genes. However, this study failed to show any significant association [24].

Future perspective: what is the impact on the management of an early symptomatic patient or a carrier?

At present, we are unable to explain the observed differences in penetrance estimates between populations. It seems likely that the effect is not due to one specific factor, but rather to a combination of both environmental and genetic factors. In addition, one can speculate that a genetic polymorphism, mitochondrial or nuclear, could account for the observed variation if the at risk alleles had different frequencies among populations.

\section{"...the delineation of genetic factors at least partly underlying the disease expression could have a significant impact on the management of both patients and carriers."}

In clinical practice, the main challenge is to administer available treatment at the earliest stage of the disease in order to halt the amyloid process and to stabilize the clinical expression. Thus, the delineation of genetic factors underlying the disease expression could have a significant impact on the management of both patients and carriers. Indeed, a better knowledge of penetrance estimates across ages in various populations is already essential to guide genetic counseling. At present, we cannot accurately foresee the onset of symptoms in a carrier. On the basis of our penetrance estimation amongst different populations, we can expect a dramatic increase in risk within particular age intervals, which serve to enhance the clinical follow up, from this time.

Unraveling the possible influence of modifier genes on the phenotype of TTR-FAP and, in particular, on the distribution of the ages of first symptoms might also provide major clues, which may help to delineate more accurately an individual disease risk. Such molecular genetic markers might contribute to the development of new therapeutic strategies. In addition, it could help determine those individuals with a higher risk of developing the disease, to be able to detect and treat them as early as possible. Furthermore, providing an orally administered and well tolerated drug, one might speculate to initiate such treatment in a carrier from the time where the individual risk of being affected has been shown to increase dramatically. Ideally, this option might halt further amyloid deposition and thus prevent onset of symptoms. We now aim to specify more accurately the carrier risk in all populations of TTR-FAP including for different TTR mutations. Additional molecular studies are clearly needed to determine the factors underlying penetrance variation.

Financial \& competing interests disclosure
The authors have no relevant affliations or financial
involvement with any organization or entity with a
financial interest in or financial conflict with the subject
matter or materials discussed in the manuscript. This
includes employment, consultancies, honoraria, stock
ownership or options, expert testimony, grants or patents
received or pending, or royalties. No writing assistance
was utilized in the production of this manuscript.

\section{Bibliography}

1. Andrade C. A peculiar form of peripheral neuropathy; familiar atypical generalized amyloidosis with special involvement of the peripheral nerves. Brain 75(3), 408-427 (1952).

2. Plante-Bordeneuve V, Lalu T, Misrahi M et al. Genotypic-phenotypic variations in a series of 65 patients with familial amyloid polyneuropathy. Neurology 51, 708-714 (1998).
3. Ikeda S, Nakazato M, Ando Y, Sobue G. Familial transthyretin-type amyloid polyneuropathy in Japan: clinical and genetic heterogeneity. Neurology 58, 1001-1007 (2002).

4. Ando Y, Nakamura M, Araki S. Transthyretin-related familial amyloidotic polyneuropathy. Arch. Neurol. 62(7), 1057-1062 (2005).

5. Herlenius G, Wilczek HE, Larsson M, Ericzon BG. Ten years of international experience with liver transplantation for familial amyloidotic polyneuropathy: results from the Familial Amyloidotic Polyneuropathy World Transplant Registry. Transplantation 77(1), 64-71 (2004).

6. Coelho T, Maia L, Martins da Silva A et al. Tafamidis (Fx-1006A): a first-in-class disease-modifying therapy for transthyretin familial amyloid polyneuropathy. Neurology 74 (9), Abstract 286, XII International Symposium on Amyloidosis 18-21 April (2010). 
7. Coelho T, Maia L, Martins da Silva A et al. Tafamidis (Fx-1006A): a first-in-class disease-modifying therapy for transthyretin familial amyloid. Amyloid 17(Suppl. 1), 38-90 (2010).

8. Sousa A, Coelho T, Barros J, Sequeiros J. Genetic epidemiology of familial amyloidotic polyneuropathy (FAP)-type I in Povoa do Varzim and Vila do Conde (north of Portugal). Am. J. Med. Genet. 60 (6), 512-521 (1995).

9. Sousa A, Andersson R, Drugge U, Holmgren G, Sandgren O. Familial amyloidotic polyneuropathy in Sweden: geographical distribution, age of onset, and prevalence. Hum. Hered. 43(5), 288-294 (1993).

10. Koike H, Misu K, Ikeda S et al. Type I (transthyretin Met30) familial amyloid polyneuropathy in Japan: early- vs late-onset form. Arch. Neurol. 59(11), 1771-1776 (2002).

11. Misu K, Hattori N, Ando Y, Ikeda S, Sobue G. Anticipation in early- but not late-onset familial amyloid polyneuropathy (TTR met 30) in Japan. Neurology 55, 451-452 (2000).

12. Alarcon F, Bourgain C, Gauthier-Villars M, Planté-Bordeneuve V, Stoppa-Lyonnet D, Bonaïti-Pellié C. PEL: an unbiased method for estimating age-dependent genetic disease risk from pedigree data unselected for family history. Genet. Epidemiol.33(5), 379-385 (2009).

13. Hellman U, Alarcon F, Lundgren HE, Suhr OB, Bonaïti-Pellié C, Planté-Bordeneuve V. Heterogeneity of penetrance in familial amyloid polyneuropathy ATTR Val30Met in the Swedish population. Amyloid 15(3), 181-186 (2008).

14. Plante-Bordeneuve V, Carayol J, Ferreira A et al. Genetic study of transthyretin amyloid neuropathies: carrier risks among French and Portuguese families. J. Med. Genet. 40 (11), E120 (2003).

15. MAC Saporta, Cruz MW, André C, Misrahi M, Bonaïti-Pellié C, Planté-Bordeneuve V. Penetrance estimation of TTR familial amyloid polyneuropathy (type I) in Brazilian families. Eur. J. Neurol. 16, 337-341 (2009).

16. Bonaïti B, Alarcon F, Bonaïti-Pellié C, Planté-Bordeneuve V. Parent-of-origin effect in transthyretin related amyloid polyneuropathy. Amyloid 16, 149-150 (2009).

17. Holmgren G, Wikström L, Lundgren HE, Suhr OB. Discordant penetrance of the trait for familial amyloidoticpolyneuropathy in two pairs of monozygotic twins. J. Int. Med. 256, 453-456 (2004).

18. Da Cunha Saporta MA, Planté-Bordeneuve V, Misrahi M, Cruz MW. Discordant expression of familial amyloid polyneuropathy in monozygotic Brazilian twins. Amyloid 16(1), 38-41 (2009).

19. Olsson M, Hellman U, Planté-Bordeneuve V, Jonasson J, Lång K, Suhr OB. Mitochondrial haplogroup is associated with the phenotype of familial amyloidosis with polyneuropathy in Swedish and French patients. Clin. Genet. 75, 163-168 (2009).
20. Bonaïti B, Olsson M, Hellman U, Suhr OB, Bonaïti-Pellie C, Planté-Bordeneuve V. TTR familial amyloid polyneuropathy: does a mitochondiral polymorphism entirely explain the parent-of-origin difference in penetrance? Eur. J. Hum. Genet. 18, 948-952 (2010).

21. Santos RX, Correia SC, Wang X et al. Alzheimer's disease: diverse aspects of mitochondrial malfunction. Int. J. Clin. Exp. Pathol. 3(6), 570-581 (2010).

22. Sousa MM, do Amaral JB, Guimaraes A, Saraiva MJM. Up-regulation of the extracellular matrix remodeling genes, biglycan, neutrophil gelatinase-associated lipocalin, and matrix metalloproteinase- 9 in familial amyloid polyneuropathy. FASEB J. 19(1), 124-126 (2005).

23. Monteiro FA, Sousa MM, Cardoso I, Amaral JB, Guimarães A, Saraiva MJ. Activation of ERK1/2 MAP kinases in familial amyloidotic polyneuropathy. J. Neurochem. 97(1), 151-161 (2006).

24. Soares ML, Coelho T, Sousa A et al. Susceptibility and modifier genes in Portuguese transthyretin V30M amyloid polyneuropathy: complexity in a single-gene disease. Hum. Mol. Genet. 15 14(4), 543-553 (2005).

\section{Website}

101. Database of transthyretin mutations: a comprehensive database of the different mutations found in the TTR gene www.ibmc.up.pt/mjsaraiva/ttrmut.html 